\title{
Lo que no te mata te hace más bárbaro. Conan como un superhombre nietzscheano
}

\author{
Conan The Barbarian | John Milius | 1982
}

Francisco Miguel Ortiz Delgado*

Universidad Nacional Autónoma de México

Recibido: 20 de marzo 2016; aprobado: 10 de noviembre 2016

\section{Resumen}

En el presente texto interpretamos al protagonista de la película Conan The Barbarian (Conan El Bárbaro) como una plausible representación del "superhombre" nietzscheano. Argumentamos que Conan posee características tanto del übermensch o superhombre como del individuo "ahistórico", descritos por Friedrich Nietzsche. Basándonos en los diversos escritos de Nietzsche, así como en algunos intérpretes de este filósofo, realizamos una exposición del comportamiento moral y la postura religiosa del Conan exhibido en el filme de John Milius, así como del de su némesis Thulsa Doom. Igualmente comparamos la cinta con otros dos personajes de la cinematografía (y el imaginario) mundial: Hércules y Mad Max. Esto con el propósito de discernir la eficacia de Milius para mostrar las cualidades únicas de Conan como superhombre nietzscheano.

Palabras clave: Superhombre nietzscheano | Religión | Valores | Ética | Violencia | Conan | Hércules.

What does not kill you makes you more barbaric. Conan as a Nietzschean superman

Abstract

In the present paper we interpret the main character of Conan The Barbarian as a plausible representation of the nietzschean "superman". We argue that Conan has qualities of the übermensch or superman as well of the "unhistorical" individual, defined by Friedrich Nietzsche. Based on the diverse texts of Nietzsche and his interpreters, we exhibit the moral behavior and the religious position of Conan and his nemesis Thulsa Doom inside the John Milius's film. We also compare the film with another two characters of world cinematography (and imagery): Hercules and Mad Max. This comparison is made with the purpose of discern Milius's efficiency to show the unique qualities of Conan as a nietzschean superman.

Keywords: Nietzschean Superman | Religion | Ethics | Values | Violence | Conan | Hercules.

El filme, desde su comienzo, nos cita una famosa máxima nietzcheana o, más precisamente, un aforismo que se encuentra en El crepúsculo de los ídolos: "Lo que no te mata te hace más fuerte", y es evidente, como vamos a ver, que la frase no es de mero uso ornamental pues, aparte de que ella misma es una enseñanza para aquel (el superhombre) que quiera superarse a sí mismo y a los demás, el director John Milius nos muestra a lo largo de toda la película que Conan tiene características de un superhombre nietzscheano -categoría de la que, tengamos en cuenta, no se debe afirmar nada absoluto porque, como bien puntualiza Dannhauser, el "concepto que Nietzsche tiene del superhombre es [...] necesariamente vago y ambiguo" (2012;796).

Conan El Bárbaro es una película única en su especie; sin remordimientos por su insensibilidad hacia la violencia y sin preocupación por lo políticamente correcto. Sus creadores nos presentan un mundo y un personaje donde la moralidad dominadora es diferente a la de nuestro mundo real: nadie, dentro del universo del filme, juzga especialmente mal a Conan por sus acciones “incorrectas" o violentas.

Originalmente concebida por Oliver Stone para ambientarse en un mundo postapocalíptico "He [John Milius, el director final de la cinta] rewrote an original screenplay drafted by Oliver Stone (in which the action takes place in a post-nuclear holocaust future)" (Smith, 1995). El director John Milius por fortuna reinserta la película en la Era Hibernia de Robert E. Howard, el creador original del universo de Conan. Esta reubicación de la trama le da un carácter ahistórico o ucrónico a la película, porque la "Era Hibernia" es inexistente en

*_fmiguelod@gmail.com 
nuestro mundo real-histórico y porque, además, tal ficticia "Era" consiste en una mescolanza de épocas de nuestra historia real (simultáneamente vemos en tal Era Hibernia del filme, y del cómic, características visuales y culturales que van desde la prehistoria hasta los últimos tiempos del Medioevo). Milius libró a la película de ser insertada en un muy plausible tiempo futuro en el que se regresaría al barbarismo; más plausible para los años ochenta del siglo $\mathrm{XX}$, debido a la escalada de la amenaza termonuclear. Aunque un "tiempo postapocalíptico" también es una temporalidad inexistente, en el sentido de que nunca ha habido un tiempo postapocalíptico postnuclear en la historia, tal tiempo sí nos permitiría ubicar la época en que transita la película dentro de un tiempo histórico real específico (se trata de un después del hoy histórico-real): el tiempo posterior a la guerra o catástrofe nuclear de nuestra realidad.

Y, si la película de John Milius hubiese sido ambientada en una época ubicada después de una hecatombe atómica estaríamos ante la adquisición de historicidad por parte de los personajes de la película. Si la película se hubiese desarrollado en un mundo postapocalíptico, la violencia y fortaleza de Conan se justificarían al estar insertas en un relato de mera supervivencia, en vez de ser (como lo es), un filme que consiste, entre otras cosas, en un relato laudatorio de las características de fortaleza -nietzscheana- de Conan. Tales características no tendrían una razón nietzscheana para ser alabadas, si estuvieran dentro del actuar por mera supervivencia, porque estarían justificadas (la fuerza, el anhelo de superación, no necesitan de justificación biológica-ética en Nietzsche). El ejercicio de la violencia en aras de un objetivo personal e individual, no concebida por el puro sobrevivir, es pues una característica del superhombre.

\section{El superhombre Bárbaro carente de una moral de esclavos}

Nuestro protagonista Conan, interpretado por Arnold Schwarzenegger, al principio de la película, cae en la esclavitud siendo un niño, por obra de Thulsa Doom y sus esbirros, y hasta que es adulto recupera su libertad. Mas Conan, a diferencia de la mayoría de los esclavos que en diversas épocas han sido manumitidos y en especial a diferencia de aquellos que han sido nacidos y criados como esclavos y liberados hasta después de muchos años de esclavitud, no continuó considerándose un (ex) esclavo ni actuó tras su liberación con una necesidad de volver a tener un amo o a alguien que le indicara qué hacer y qué no.

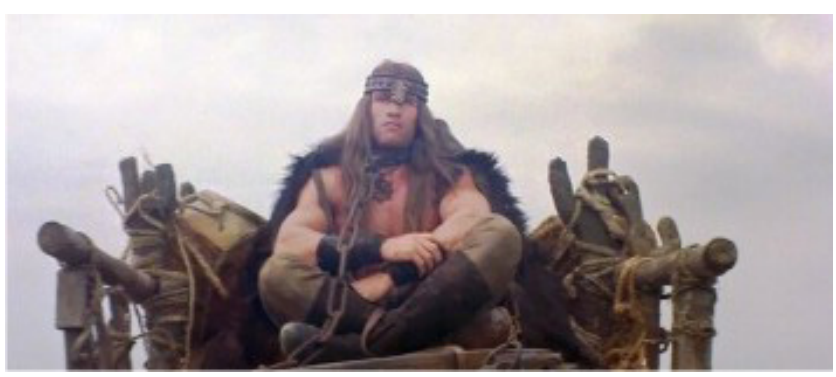

El punto es claro, pese a sus años de esclavitud, el personaje principal nunca adquiere una "moral de esclavo", aquella que para Nietzsche se caracteriza por un comportamiento de sumisión ante los semejantes y que se distingue por encumbrar valores como el perdón, la misericordia o la paz. Es decir, aquella ideología que, por nacer de la docilidad, alaba a ciertos valores representativos o equivalentes a los de una religión de esclavos como lo es, para el filósofo alemán, el judaísmo o el cristianismo. "Pues hoy día señorea la pequeña gente, que predica la resignación, la conformidad sumisa, la cordura, la laboriosidad, la consideración y el extenso catálogo de las pequeñas virtudes./ Lo que tiene mentalidad de mujer y de siervo y, particularmente, la plebe vil, pretende hoy gobernar todo destino humano, ¡oh, asco! ¡Asco! ¡Asco!” (Nietzsche, 2001:187). Estas pequeñas virtudes son las que conforman y dan forma a la "moral de esclavos"; virtudes que nunca adquiere Conan. Al leer las últimas palabras de Nietzsche comprendemos mejor las acciones de nuestro protagonista y nos llevan a entenderlo como un individuo que nunca llega a ser-vil.

La actitud del Conan de Milius ante su nuevamente adquirida libertad física, una vez adulto, es lo que nos puede llevar a interpretarlo como un superhombre nato. Cuando su amo lo libera, Conan no le dice que no desea ser libre, ni que desea continuar con él, su señor, ni siquiera le agradece; sin dudarlo, el Bárbaro simplemente huye. Éste es un hombre que no extraña la servilidad, que no se conforma ni se resigna. Puede pertenecer a la camada de superhombres de los que dice Nietzsche que "Su desprecio, hombres superiores, me hace abrigar esperanza, puesto que los hombres del gran desprecio son los hombres de la gran reverencia./ Su desesperación los honra, puesto que no han aprendido a resignarse; no han aprendido las pequeñas corduras." (Nietzsche, 2001;187). Conan desprecia a su mundo, se desespera con su mundo, y esto es palpable en su respuesta a la pregunta ¿qué es lo mejor en la vida?, a la que replica, 
"Aplastar a tus enemigos, ver cómo los conducen ante ti y oír los lamentos de sus mujeres". Por igual muestra su desprecio de gran reverencia, al mundo, cuando se le pregunta, enfrente de unos viejos edificios, si había visto una civilización antigua (y aviesa), y dice tajante "No. No perdamos el tiempo".

Veamos detenidamente, Conan recupera su libertad y luego muestra que adolece de ataduras espirituales, tanto religiosas como éticas. El guerrero de Milius prefiere el placer sobre el dolor, es decir, vemos que nunca rechaza lo voluptuoso; ni a las mujeres, ni a la comida en exceso, ni a las riquezas, como las rechazaría un buen monje. "Toda forma de placer y diversión fue permitida", dice el cronista de Conan sobre uno de sus festejos. "Se trata de una vida [como la que intentó vivir, y que siempre alabó, el propio Nietzsche] que no se vive en aras de una necesidad, sino a partir de una producción, una productividad que se convierte en el elemento central del modo de vida" (Frey, 2013:19). O, desde otro ángulo, ese hombre belicoso representado en el filme vive siempre en el mundo real, en contraste con el mundo ficticio metafísico-teológico en el que viven los hombres religiosos, y no aspira, ni desea, ni tal vez tampoco imagina, tales mundos ficticios metafísicoteológicos creados por filósofos y monjes pervertidos. Por eso dice el filósofo alemán “[...] no hay en mí nada de fundador de una religión. Las religiones son asuntos del populacho. He tenido necesidad de lavarme las manos después de haberme puesto en contacto con hombres religiosos..." (Nietzsche, 1987:196), lo mismo le sucede al Bárbaro del filme, desprecia las religiones (institucionalizadas), y aún va más allá, Conan tiene la necesidad no sólo de lavarse las manos sino de usarlas para aniquilar a los magos y a los religiosos. Porque para Nietzsche el hombre religioso moderno, específicamente el cristiano, denigra a la Humanidad, la lleva a una decadencia, por eso, nuestro filósofo dice no querer "creyentes", no buscar la beatificación ni la santidad (Nietzsche, 1987;197); de forma análoga Conan no desea seguidores creyentes ni mucho menos muestra anhelar una santidad.

Las creencias religiosas del cristianismo, para Nietzsche, están repletas de una moralidad de conformismo, de la moral de esclavos, que hace sentir bien a los débiles, a los que no son ni guerreros ni aristócratas inmorales, en sus humilladas vidas y en sus derrotas cotidianas; Conan no tiene nada de cristiano pues ésta religión enseña la práctica de la piedad y el eliminar los impulsos de venganza.
"Únicamente hasta que uno toma en serio la perspectiva de Nietzsche sobre la utilidad y hostilidad de la religiones frente a la vida, más allá de cualquier contenido de verdad, es posible reconstruir el horizonte interpretativo desde el cual éste se aproximó a la historia de las religiones" (Frey, 2013;234): yo diría que únicamente hasta que uno toma en serio la perspectiva o, mejor dicho, la actitud de Conan sobre las religiones institucionalizadas es que es posible comprender la rivalidad entre este personaje y su némesis, el líder religioso, Thulsa Doom. Porque, finalmente, la confrontación entre Conan y Thulsa Doom bien puede corresponder a la confrontación religión-primitiva ${ }^{1} /$ barbarie contra religión-institucionalizada ${ }^{2} /$ civilización. $^{2}$

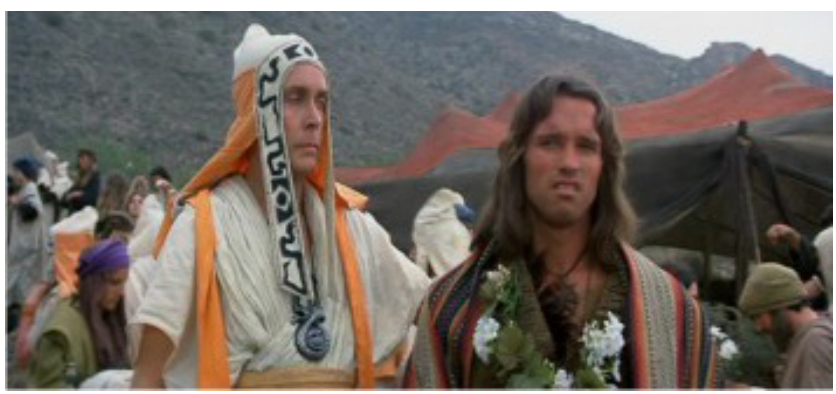

El continuo actuar, el actuar sin deliberar en demasía (pues también se cultivó en la "poesía de Khitai, la filosofía de Sung”), sin preocuparse de una moralidad opresora, ni de dilemas éticos que agobian a otros héroes, convierte a Conan en un superhombre porque hace aflorar plenamente su voluntad de poder y esto se debe, a su vez, a la mencionada ausencia de ataduras espirituales y a la ausencia en él de virtudes cristianas o de esclavo, ambas ausencias le llevan a ser mejor, a superarse, a elevarse sobre los demás individuos. "La voluntad de poder [...] No es [...] solamente lucha, voluntad de perseverar en el ser, instinto de conservación, sino voluntad de rebasar. En el nivel superior se vuelve generosidad, voluntad de ser y de conciencia, voluntad de posesión total de la existencia y de sí mismo" (Lefebvre, 1987;108). El Bárbaro prefiere seguir viviendo y combatiendo en el mundo real-físico y no en el teológico, movido por un ideal de guerrero y no de esclavo: la venganza (que es denostada por la moral cristiana). Este camino le da una posesión total de sí mismo, no es títere de moral teológica alguna. "Puede uno llegar a superarse por múltiplos medios y caminos: eso es cosa tuya" (Nietzsche, 1987 B:284). Conan se supera en la venganza contra los asesinos de sus padres, contra Thulsa Doom y los suyos, es decir, simbólicamente, se supera en la venganza contra la religión. El superhombre 
en Nietzsche puede ser interpretado, en gran parte, como la superación de Dios y de la religión. "En otro tiempo, cuando se miraba a los mares lejanos se decía: 'Dios'; pero ahora yo os he enseñado a decir: 'Superhombre'. [...] ¿Podríais crear un Dios? ¡Pues entonces no me habléis de dioses! Sin embargo, podríais crear el Superhombre." (Nietzsche, 1987 B:270). En el filme se aprecia que el bárbaro elude creer, alabar o incluso hablar de un mundo "irreal" trascendental perteneciente a cualesquiera dioses, inventado por sacerdotes y teólogos decadentes; sólo continúa mencionando a su dios Crom como por una costumbre, para que lo fortalezca en este mundo terrenal, a modo de incentivo: nunca lo menciona para pedirle un beneficio en el Más Allá porque lo único que le interesa a Crom, según refiere el mismo Conan, es que sus fieles sepan la "regla del acero".

El análisis de la filosofía de Nietzsche nos permite ver al Conan de John Milius como un individuo con valores aristocráticos, elevados, como los que el filósofo afirma tiene el superhombre. Nuestro personaje no profesa una religión con una ética parecida a la del judaísmo o al cristianismo, como lo haría una "casta inferior". Conan no tiene un credo que inste a seguir una moral conformista y de compasión. Por esto es que hay un paralelismo entre tal personaje y los valores nietzscheanos: "El ataque de Nietzsche al antiguo judaísmo sacerdotal se dio sin concesión alguna. Los sacerdotes judíos habrían difundido la representación errónea de un 'orden moral universal' de pecado, culpa, castigo, arrepentimiento, compasión y amor al prójimo" (Frey, 2005;159). El ataque de Conan a los sacerdotes fue más literal en el filme. Aunque la religión de Thulsa Doom también es violenta y no parece ser una basada en la culpa y el amor, busca sin embargo esclavizar con mentiras y artificios: se afirma de su secta que son unos "embaucadores. Matan gente durante la noche". Doom cree que el engañar-convencer-controlar a los hombres es poder, lo muestra cuando le ordena a una mujer lanzarse desde lo alto de un risco provocándole su muerte, afirma que eso es poder; y trata de engañar al Bárbaro al decirle que él le dio su deseo del corazón o su "voluntad de vivir [...] ¿Qué será de tu mundo sin mí?”, pero Conan no se deja engañar ("no confíes en nadie", así lo crió su padre). La confrontación entre Conan y Doom la podemos ver como metáfora del enfrentamiento entre Nietzsche y los valores e instituciones judeocristianos, los cuales matan no de forma literal sino metafórica: asesinan el (verdadero y más auténtico) espíritu humano.

La creencia del bárbaro es cuasimonoteísta y de los fuertes; Crom es el dios (guerrero) principal (quizá único) y pertenece a las creencias de una sociedad beligerante y victoriosa. Como le refiere su padre a Conan, cuando los gigantes le robaron el secreto del acero (como guerrero tiene que saber de armas y de su hechura), Crom se enojó "y la tierra tembló. El fuego y el viento cayeron sobre los gigantes [...]": esto es muestra de una divinidad beligerante y de moral guerrera. Su dios no le impone a Conan, en ningún momento, un severo conjunto de normas éticas (de índole judeocristiana) que le proveyeran de miramientos y de tapujos; no sigue la axiología propia de un panteón con un dios único y solitario creado a partir de la derrota, como lo fue el Dios de los judíos (Frey, 2005;155-164). Crom es un dios violento, como la sociedad a la que pertenece Conan, al igual que los dioses aristocráticos de los griegos fueron violentos porque pertenecían a una cultura dominada por una aristocracia bélica. Crom es diferente al Dios cristiano que es amoroso, piadoso, pacífico, como lo fue la sociedad judía de la Antigüedad que estaba siendo perseguida y esclavizada cuando surgió su Dios único (Frey, 2007:187). Crom tiene más parecido a los dioses principales de politeísmos como el nórdico o el griego, tiene más similitudes con Odín o con Zeus por ser un dios guerrero, una deidad que no es de paz y de amor sino de fuerza y de poder. El ascetismo, característica de los religiosos cristianos y de otros credos, es lo peor que le puede suceder al ser humano, el cual, a decir de Nietzsche, debe hacer sobresalir sus impulsos fuertes (Garzón, 1985:564), no reprimirlos. Y sacar sus impulsos fuertes en definitiva Conan sí lo hace, en mayor o menor medida, de diversas formas: alimenticia, beligerante, sexual, vindicativa, etc.

\section{El hombre ahistórico, el triunfo amoral sobre las instituciones y la civilización}

Consideramos que el bárbaro es capaz de alejar las ataduras espirituales, religiosas y ético-metafísicas, de sí mismo debido a que, en el filme, tiene las alabadas características nietzscheanas de un hombre ahistórico; no le pesan ni su historia, ni ninguna costumbre o tradición, ni nacionalismos ridículos, ni moralidades.

[...] la tesis propuesta a la reflexión del lector: que lo ahistórico y lo histórico son en igual medida necesarios para la salud de un individuo, de un pueblo o de una cultura. En este sentido cualquiera puede entender esta observación: por mucho que la ciencia y el sentimiento histórico de un hombre sea muy limitado, por mucho que su Horizonte 
sea tan estrecho como el de los habitantes del valle de los Alpes [o el horizonte del habitante de un bosque perdido como Conan], por mucho que manifieste en cada juicio una injusticia y en cada experiencia la creencia errónea de ser el primero en formularla, este hombre, pese a todas sus injusticias y errores, conservará una insuperable salud y vigor y alegrará cualquier mirada. (Nietzsche, 2003;45).

Conan fue criado sin ninguna atadura espiritualmoral fuerte, no se muestra que alguien se las haya inculcado. Una vez que se le presentan las cuestiones espirituales las rechaza con facilidad y no le son nunca atractivas; no le interesa, por ejemplo, el hecho de que pueda haber un dios superior a Crom, como le sugiere su compañero Subotai. Y la elevación por sobre las ataduras y especulaciones morales de los débiles, de la religión judeocristiana, es, para Nietzsche, una característica del superhombre, esto es, ser más que cualquier hombre. “[...] recogí la palabra 'Superhombre' y esta doctrina: el hombre es una cosa que debe de ser superada; el hombre ha de ser un puente, y no un fin: gozoso de su mediodía y de su tarde" (Nietzsche, 1987 B;283). En Nietzsche el individuo ahistórico es el que más cambios realiza en la política (y sin llegar a ser gobernante) y en la historia puesto que los hombres grandiosos de la Historia son los hombres ahistóricos-actuantes (Ortiz, 2016).

Y, hablando de lo no-histórico, es muy sugerente que en la Era Hiperborea, en la que vive Conan, se entremezclan y se confunden intencionalmente diferentes épocas históricas de la Humanidad; el protagonista se encuentra tanto a personas prehistóricas del 10,000 a.C. como a medio-orientales del siglo $\mathrm{X}$ a.C., a bárbaros europeos del s. V d.C., a piratas del s. XVI y a muchos más. Son notables la imprecisión y la gran amplitud temporal, con que el cronista de Conan designa a la época ficticia en que vivió éste: "Entre la época en que los océanos bebieron Atlantis y el surgimiento de los hijos de Aryas". El mundo de Conan no tiene clara referencia histórica, lo que podría permitir, sugerimos, plantear con mayor facilidad la existencia de superhombres no atados a una clara tradición de su pueblo. No hay, por ejemplo, en la película, principios nítidos de un nacionalismo al no haber algo que distinga con certeza un pueblo de otro como a una época de otra. Conan tiene sólo una vaga conciencia sobre su propio pasado y hay poco que le permita aclarar su herencia cultural que, de cualquier forma, no le interesa en demasía.

El individuo ahistórico no está aturdido por su pasado, ni está anquilosado, ni cansado, ni apesadumbrado por su historia o tradiciones. Nietzsche, en su II Intempestiva llamada Sobre la utilidad y el progreso de la historia para la vida, elogia a los bárbaros por regenerar a Europa durante la Antigüedad Tardía (Nietzsche, 2003). Es decir, son los "bárbaros" como los godos, los vándalos o los alanos quienes tienen el mérito de haber re-creado a Europa. Cuando en el siglo IV y V el Imperio Romano, que ya era oficialmente cristiano, está siendo acosado intensamente por pueblos menos civilizados, cae ante estas nuevas culturas debido a que, de acuerdo con Nietzsche, a Roma le pesaba inmensamente su historia. Por más que Roma quisiera imitar, desde el siglo III d.C., a sus mejores representantes de tiempos pretéritos, ella ya estaba petrificada y decadente $y$, en vez de que su historia fuera motivo de impulso, era un lastre que le impedía avanzar.

De manera análoga a la historia de los últimos años de Roma y su caída final por obra de los bárbaros, la película nos muestra que Conan triunfa sobre organizaciones creadas por hombres desde antiguo: triunfa sobre las instituciones como el esclavismo y la (impotente) monarquía (que nada puede contra Thulsa Doom). Pero el mayor éxito lo obtiene contra la llamada “Torre de la Serpiente", un vetusto y degradado edificio donde tienen su base de operaciones los sacerdotes del antagonista Thulsa Doom. Tales victorias se deben en gran parte, sugiero, a esa fortaleza barbárica proveniente de lo unhistorich, lo "no histórico", lo que le otorga a Conan una "insuperable salud y vigor", en contraste con la tangible decadencia o petrificación de todas aquellas instituciones.

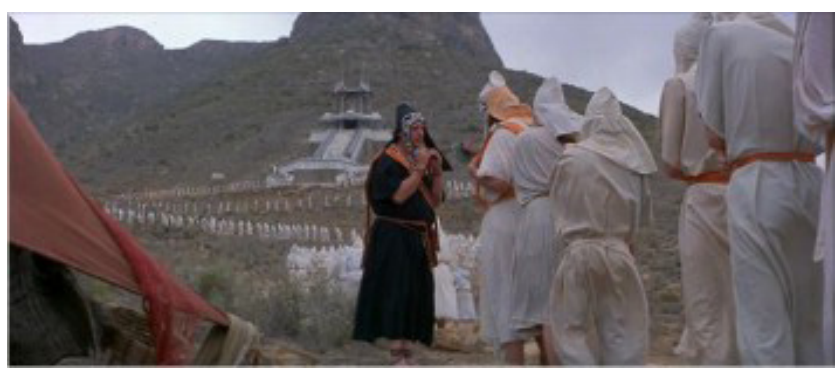

$\mathrm{Al}$ adolecer de la casuística ética de esclavos provista por una religión o una filosofía atávica nuestro guerrero poseía mayores oportunidades de conseguir imponer su venganza contra Thulsa Doom: por ejemplo, no tiene inconveniente alguno en unirse a ladrones o practicar hechicería para lograr sus objetivos. Nuestro personaje, puede vivir a través de toda la Era Hiboria sin cargar ideales falsos que, de acuerdo con el aristocratismo de espada de Nietzsche, lo hubiesen disminuido física y espiritualmente, le hubieran extraído su salud. Se tra- 
ta, por esto, de un protagonista muy diferente a otros filmes del género "Swords\&Sorcery" o del mitológico-fantástico, estamos ante un individuo plenamente nietzscheano. No estamos pues ante un Perseo de Furia de Titanes (Desmond Davis, 1981) quien es motivado a luchar contra múltiples peligros por su amor hacia Andrómeda y para ajusticiar las tropelías de Calibos; ni mucho menos estamos ante las aventuras del héroe HeMan que sólo desea atrapar a los esbirros del ambicioso Skeletor (Masters of the Universe, Gary Goddard, 1987) porque es su "deber". Además, existen otros héroes del mismo género que, aunque también amorales, palidecen ante la amoralidad y el pragmatismo de Conan: el ladrón Bek en Dioses de Egipto (Alex Proyas, 2016) es escéptico y burlón hacia los dioses pero, finalmente, ayuda al "bien" representado en Horus, aunque sea por el amor que le tiene a su damisela; otro ejemplo, los únicos guerreros en la serie para televisión Juego de Tronos (2011-) que tienen características del superhombre plenamente inmoral son Tywin Lannister y Jaime Lannister, sin embargo, el primero pierde su superioridad al intentar institucionalizarse para implantar una dinastía (pierde su salud y su vigor ahistóricos) y el segundo, conforme avanza la saga, adquiere ideales caballerescos con tintes muy (cristianamente) morales (otro individuo con características amorales nietzscheanas es Peter Baelish, sin embargo, éste no es un guerrero y además actúa mediante el engaño y la apariencia, algo muy poco perteneciente a las virtudes de la aristocracia de espada). Conan jamás se institucionaliza, jamás se vuelve sedentario (al menos no en la película de Millius), jamás se hace civilizado por completo (dejaría de ser bárbaro si lo hiciera), jamás se hace caballero de ideales románticos (llora a Valeria su amada muerta, la venga, pero hasta ahí), jamás pierde su vigor ni su voluntad de poder.

\section{Thulsa Doom o el sacerdote decadente}

El antagonista, Thulsa Doom, bien puede ser identificado con lo civilizado, lo sedentario, lo degradado (donde alguna vez había habido vigor guerrero) y lo falso. En la segunda mitad de la película encontramos a Doom como un alto jerarca religioso quien es un manipulador de las masas y que emplea la falsificable palabra y la hechicería para controlarlas. Thulsa Doom parece que ya no puede emplear más la espada para dominar $\mathrm{y}$ atormentar a los indefensos pobladores no-guerre- ros de los diferentes reinos, al menos no como antes. Y el discurso religioso y la magia y la milagrería evitan que la casta inferior esclavizada en la Montaña de la Serpiente y en otros templos del culto de la víbora se levante contra el jerarca. Sólo Conan y sus ayudantes combaten a los opresores, pero no para oprimir a su vez ni para liberar a los subyugados, quienes por su característica docilidad, su moral de esclavos, nunca piden ser liberados, sino porque ese combatir -vengativo- es parte de su ser.

El rey Osric (interpretado por Max Von Sidow) es uno de los pocos que desean levantarse contra Thulsa Doom, no sólo porque éste haya convencido a su hija para seguirlo sino porque es otro personaje que no tuvo moral de esclavo. Pero en el momento en que conoce a Conan se encuentra ya anquilosado, "Una vez fue un poderosos hombre Norteño". Pese a su situación, muestra su todavía elevado espíritu, y sobre el Bárbaro y sus compañeros Valeria y Subotai (un afamado ladrón pero también guerrero-arquero), y sobre la religión implementada por Thulsa Doom en diversas regiones aledañas a su reino y en su propio territorio, da el siguiente discurso:

Thulsa Doom. Ese semidios me ha irritado durante años. Serpientes en mi bella ciudad. Al oeste, Nemedia, Aquilonia. Al sur, Koth, Stygia. ¡Serpientes! En todas partes, esas malditas torres. Ustedes solos vencieron a sus guardias. ¿Y qué son? ¡Ladrones! [...] Y mi propia hija ha caído bajo este hechizo de Thulsa Doom. ¿Hay en su mano una daga como ésta para mi? Lo sigue como una esclava, buscando la verdad de su alma, como si yo no pudiera dársela.

Hay que notar que el rey no comienza hablando del rapto de su hijala Princesa, sino que comienza comentando la molestia que es Thulsa Doom, un hechicero que incrementa su dominio de almas desprevenidas. Le da vergüenza que los que aparentemente son unos ladrones hayan derrotado a los esbirros de Doom y que él, siendo un guerrero, no haya podido contra aquellos. El énfasis nietzscheano en esta secuencia de la película es claro porque según el filósofo hasta los ladrones, quienes también viven por medio del engaño, son superiores a los hombres de religión. Nos asegura el filósofo alemán: "Despreciamos [...] al hombre desconfiado, al de mirada huidiza, al que se humilla, al canalla que se deja maltratar [como los cristianos que se mortifican a sí mismos], al mendigo adulador $\mathrm{y}$, ante todo, al mentiroso [como los sacerdotes y hechiceros que basan su oficio en el engaño]” (Nietzsche, 1986;202). "[Para Nietzsche] 
Todo es preferible al ser torpe, a la bestezuela de rebaño bonachona y bobalicona [como los individuos fanáticos de la religión], todo, incluso el criminal [los ladrones incluidos] [...]" (Lefebvre, 1987;153). Los ladrones no hechizan, no utilizan esos artilugios del hombre inferior; tampoco Conan y sus compañeros emplean al por mayor la hechicería.

Al rey Osric no le importan ni sus riquezas ni su reino, lo que anhela es derrotar a Thulsa Doom pero no para ver a su hija liberada en sí, sino por haber sido afrentado por este último personaje. Cuando habla del rapto de la Princesa no habla con tristeza sino con aires vengativos y de odio por habérsele faltado al respeto y con un sentimiento de deshonor al ver a su heredera como esclava, no sólo de forma espiritual sino que de manera literal también. La Princesa es, en esta representación fílmica, el dechado del "hombre inferior" nietzscheano, de aquel que siempre necesita de alguien que lo domine de manera absoluta para poder vivir "bien". La esclavitud de ella es voluntaria, por su propia elección, pues en algún momento llegó al extremo de seguir al sacerdote enemigo de su propio padre. La religión posee el "arte de falsificación y [...] automendicidad propias de la impotencia, con el esplendor de la virtud renunciadora, callada, expectante, como si la debilidad misma del débil [...] fuese un logro voluntario, algo querido, elegido [...]" (Nietzsche, 2002:60-61).

Thulsa Doom es entonces el líder de un culto mágico $y$ es un hechicero que ata espiritualmente a sus subordinados pero, parece, que tal personaje, por su mismo actuar opresor, tiene ciertas cualidades de superhombre, y a la vez tiene otras que evitan que lo sea -según apunto a continuación. Robert E. Howard, como Nietzsche, otorgó primacía a la fuerza sobre el pensamiento como factor determinante de la formación de un gran hombre (pero Howard, a diferencia de Nietzsche, sí fue en vida un hombre vigoroso y activo, un verdadero tejano que practicaba el box, la pesca o el arte del lanzamiento de cuchillos -según apunta el documental Conan. The rise of a fantasy legend). Thulsa Doom en sus últimos días ya no emplea la fuerza física sino el engaño (que para Nietzsche es un arte mujeril porque es contrario al vigor y a la fuerza física que son lo masculino), para imponerse, y tal actuar lo demerita. Doom es un individuo que se deja llevar por su voluntad de -adquirir- poder, debe ser concebido como una serpiente ahistórica convertida en hombre que quiere dominar a los otros, pero sus nuevos métodos no son ya las mejores maneras para lograr su cometido.

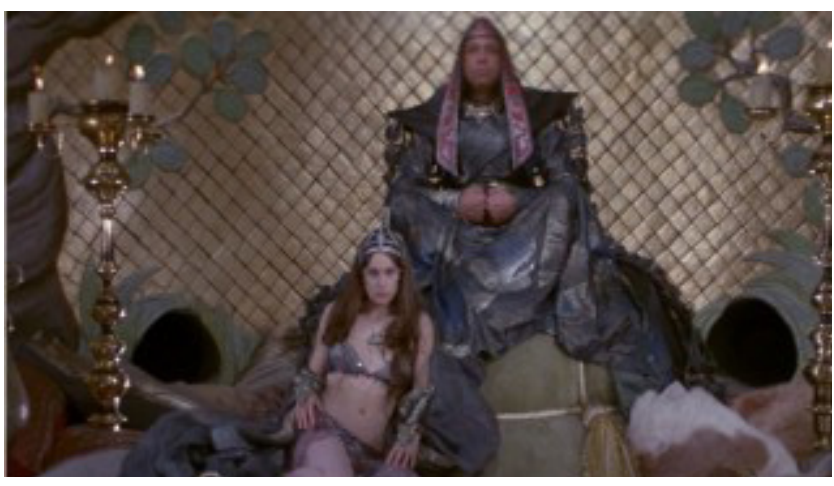

Doom puede ser interpretado como un individuo ahistórico porque es un individuo del mero actuar: tampoco le pesa la historia ni las tradiciones. Coincidentemente, en el filme se transforma en un animal, una serpiente que parece no tener memoria histórica; "Entonces, al mismo tiempo que el hombre dice 'me acuerdo', envidia al animal ${ }^{3}$ que olvida inmediatamente mientras observa cómo ese instante presente llega a morir realmente" (Nietzsche, 2003:41). Pero el simple actuar por actuar, por ímpetu, no convierte a alguien en übermensch, lo hace el vigor físico, el aristocratismo, lo masculino, la honestidad, la fuerza mental y otras características más. Y Thulsa Doom adolece ya, en la segunda mitad de la película, de todo lo anterior, puesto que está ya anquilosado, es femenino, deshonesto... y confiesa que "cuando era más joven, hubo un tiempo en que busqué el acero. Cuando el acero me importaba más que el oro o las joyas.” Doom, en la segunda parte del filme, tiene más seguidores débiles que fuertes, tiene tras de sí a las masas degradadas y degradantes y es femenino porque engaña, porque sigue una moral de débiles y porque ahora cree más en la magia que en la fuerza. La serpiente que es Thulsa Doom posee aún el vigor propio e inseparable a un individuo ahistórico (Nietzsche, 2003:45), pero ya no es más un superhombre.

Según hemos dado a entender, Conan the Barbarian no es una burda oda a la violencia, como algunos podrían argumentar, como tampoco lo es la filosofía nietzscheana. Nietzsche no alabó a la violencia sino al actuar puro, con vigor y sin miramientos; colocó a la fuerza por sobre el pensamiento, al menos sobre cierto pensamiento de esclavos y opresor. "Vivir es sustancialmente despojar, herir, violentar lo que es extraño y débil, oprimirlo, imponerle duramente sus propias formas, asimilarlo [...]" (Nietzsche, 1986:199), es decir, únicamente se debe de imponer violencia sobre lo inferior para mejorarlo, tal es un punto clave para la existencia del ser humano. El mejor representante histórico del ser-actuante, 
es el aristócrata por espada o fusil; no se olvide que a uno de los personajes que más admiró Nietzsche fue Napoleón Bonaparte. Éste, como Conan, adquirió un reino o, mejor dicho, un imperio para sí, empero, nunca cesó su actividad guerrera y de superación.

La razón por la cual el bárbaro de Milius venció a Thulsa Doom la podemos dilucidar mejor a través de la filosofía nietzscheana, la cual nos arroja luces sobre el significado de que Conan sea un guerrero y su enemigo un sacerdote:

Ya se habrá adivinado que la manera sacerdotal de valorar puede desviarse muy fácilmente de la caballeresco-aristocrática y llegar luego convertirse en su antítesis; en especial impulsa a ello toda ocasión en que la casta de los sacerdotes [evidentemente representada por Thulsa Doom] y la casta de los guerreros [representada por Conan] se enfrentan a causa de los celos y no quieren llegar a un acuerdo sobre el precio a pagar. Los juicios de valor caballeresco-aristocráticos tienen como presupuesto una constitución física poderosa, una salud floreciente, rica, incluso desbordante, junto con lo que condiciona el mantenimiento de la misma, es decir, la guerra, las aventuras, la caza, la danza, las peleas y, en general, todo lo que la actividad fuerte, libre regocijada lleva consigo. La manera noble-sacerdotal de valorar tiene -lo hemos visto- otros presupuestos: ¡las cosas les van muy mal cuando aparece la guerra! (Nietzsche, 2002;45).

Thulsa Doom fue vencido; porque ya tenía muy poco de superhombre; porque en el momento de su batalla ya pertenecía a la casta sacerdotal; porque sus valoraciones eran débiles (a modo de ejemplo, el lamentarse de la pérdida de los objetos de los que se es dueño es de viles y débiles, como cuando le dice al Bárbaro "Irrumpiste en mi casa, robaste mi propiedad, mataste a mis criados y mascotas. Y eso es lo que más me acongoja”); porque (cabe decir que consideramos que en la película revisada ni Conan es un "héroe" ni Thulsa Doom es un "villano", ambos estarían "más allá del bien y del mal”), al servirse de la religión, se está atando a la tradición -religiosa y hechicera- y a una ética, pierde así la buena perspectiva humana y muere por el peso metafórico de lo histórico. El animal-serpiente-hechicero se convierte en hombre, se vuelve consciente de su historia y el peso de ésta lo aplasta.

\section{Conan contra Hércules}

Pocos filmes del género (Sword E Sorcery/aventura) se acercan a una profundidad filosófica como Conan the
Barbarian, obra que, sin embargo, surge de una simpleza argumental. Existe un personaje, Hércules, que, dentro de los antiguos mitos griegos, está y actúa más allá del bien y del mal (cristianos). Por eso es que se le puede cotejar con Conan, del que sugerimos está por encima de los valores cristianos. Hércules, en varias de sus re-presentaciones fílmicas, como la italiana Ercole e la regina di Lidia de Pietro Francisci (1959) o la reciente Hercules de Brett Ratner (2014), ha llegado a ser mostrado como un personaje con características del hombre superior nietzscheano, cercano en esto al Bárbaro de Conan the Barbarian, aún cuando lo es más en sus antiguas historias originales. Aquel personaje mitológico es el prototipo del hombre de acción desde la Antigüedad, es el maldito por los dioses, y es el hombre con superfuerza que no tiene miramientos en rebelarse y actuar en contra de esos mismos dioses.

Los griegos y los romanos tuvieron a Hércules como el más grande de los héroes porque hizo proezas de dioses. Pero a él no le importó ser un sacrílego y se comparó y peleó físicamente contra las mismas divinidades, como Nietzsche combatió intelectualmente al dios Yahvé. Hércules suplantó en su trabajo al Titán Atlas y liberó a Prometeo, pese a que éste fue condenado a vivir atado en una roca por el mismo Zeus (se rebeló contra el castigo propinado a quien robó el secreto del progreso). Y el susodicho personaje ha sido material para muchos dramaturgos antiguos, uno de éstos fue el filósofo Séneca quien, en su obra Hercules, nos lo muestra (basándose en una versión del mito) cuando sufre una terrible locura que arrasa todo y que lo empuja a asesinar a su esposa y a sus hijos. Dice Hércules en la tragedia citada: "A la restante prole arrasaré, y todos sus escondites. ¿Por qué me demoro? Mayor guerra me queda en Micenas: que, volcados por nuestras manos sus ciclópeos peñascos, se derrumben.” (Séneca, 1998:36), esto es la violencia llevada a lo trágico no vista en ninguna de sus películas modernas... La demencia de Hércules es una que es similar, en lo violento, a la locura que sufrió Nietzsche y que lo llevó a intentar arrasar con todo lo acostumbrado éticamente, a intentar destruir gran parte de la ética Occidental y que lo empujó a asesinar a Dios.

Igualmente, una genial locura fue la que tuvo Robert E. Howard, la cual lo llevó a crear a Conan y a su mundo en una sola noche. Parece que en Conan y en Hércules, como en Nietzsche y en Howard, la locura y la violencia están directamente relacionadas. El director de nuestra película, John Milius, nos habla del proceso que Howard vivió para crear a Conan el cimeriano y a su mundo; se 
trata de un comentario que, al final, nos habla del proceso creador en general.

Tenía un gran don para captar ese ambiente siniestro de muerte y furia y la enloquecida mentalidad wagneriana [por cierto, rcuérdese que Wagner era admirado por Nietzsche y, en un tiempo, fue su amigo]. Estaba convencido de que su pueblo quería exterminarlo. [Iba a casa y] Tapaba sus ventanas con madera y cargaba sus fusiles. Qué [completamente] loco. Lo mejor de todo fue que una noche estaba solo y sintió que una sombra lo abrumó por detrás. Y sabía que Conan estaba detrás de él con una [sic] hacha enorme. Y Conan le dice: "Quédate donde estás y escribe". "Si no haces lo que digo, voy a partirte por la mitad". Estaba aterrorizado porque de Conan emana tal poder y temor. De reojo podía ver que la [sic] hacha brillaba. Y así escribió toda la noche. [...] Y yo he sentido eso siempre [que Conan estaba siempre atrás de él mientras filmaba]. [Documental Conan the Barbarian Unchained].

Aquí estamos ante la locura como creadora y destructora a la vez. Conan está aquí retratado como un daimon inspiracional, como el que, según los griegos antiguos, tiene cada persona. Pero se trata de un daimon que a la vez que inspira puede traer destrucción y desesperanza, exactamente igual que el daimon (mal traducido como demonio) que una noche se le presentó a Nietzsche y le inspiró su particular idea sobre el Eterno Retorno, una parte de su filosofía que puede ser tanto estimulante, para los individuos superiores, como deprimente, para los que no pueden lidiar con ella.

Pero, a diferencia de Conan, Hércules no ha recibido una digna, seria o atractiva película (hasta donde sé) en que se le represente completamente como el héroe amoral y con graves errores que fue, tampoco hay película en la que se le muestre por encima de los cánones éticos de los mortales debido a su condición divina, o donde se exhiba su superioridad lograda a través de un actuar en el que no se tiene cuidado por las consecuencias de los propios actos. Es decir, no hay una película donde veamos a un Hércules "nietzscheano", en cambio, en la obra de Séneca sí podemos ver un tipo de Hércules con características de superhombre.

En la arriba mencionada película Ercole e la regina di Lidia de 1959, Hércules es pintado como un héroe unidimensional que combate orientales y egipcios y en la versión de 2014 vemos a una versión evemerista ${ }^{4}$ y supuestamente realista de un aventurero que, oh desventura, engaña a los demás para agrandar sus hazañas. En la Era de los medios audiovisuales es más claro que los perso- najes clásicos grecorromanos han perdido su puesto primordial en el imaginario popular (los mitos grecolatinos aún se representaban con asuidad hasta el siglo XIX) y no han recibido lo que se merecen, ni han sido tratados como lo que son: películas serias sobre temas serios. Los clásicos antiguos han sido suplantados por los mitos y héroes estadounidenses: el mismo Conan, Superman o Capitán América (una proeza que, por cierto, no había sido lograda, en la escala que hoy en día lo vemos, ni por el imperialismo cultural de los británicos del XIX o el XX, ni por ningún otro imperio previo). En los siglos XX y XXI Hércules es un héroe anodino, castrado $\mathrm{y}$ cristianizado, acoplado para las audiencias infantiles, despojado de sus virtudes salvajes y aristocratizantes caras a Nietzsche.

\section{Comparación final. Conan contra Mad Max}

Saber que Conan the Barbarian pudo haber sido ambientado en un mundo postapocalíptico (después de una guerra termonuclear), como mencionamos al principio de este texto, nos puede dar la libertad de cotejarlo con las películas de la saga de Mad Max que, no perteneciendo al mismo género de Sword E Sorcery, tienen el mismo leitmotiv: la fuerza, la fortaleza y la violencia humanas. El personaje de Mad Max, quien por cierto, como su nombre lo indica, también padece constantes ataques de locura, está bien ubicado históricamente: la época posterior a una guerra atómica mundial en un punto en el futuro. Max Rhodakanaty, el protagonista, también tiene características del superhombre nietzscheano: amoralidad, continuo-actuar, irreligiosidad, desprecio al sedentarismo inútil, desprecio e indiferencia ante los débiles o hacia la historia o la mitohistoria (véase Mad Max 3 y la actitud del protagonista ante los niños que guardan el pasado a través de una especie de historia oral).

Tanto a Conan como a Max les fueron desencadenadas sus características de superhombre por el asesinato de sus familias, ambos cayeron en una locura de genios-guerreros a través de un shock que los separó de tajo de la vida mullida, tranquila, conformista y amorosa de los débiles y, finalmente, lograron obtener la superioridad sobre los demás al olvidarse, repudiar y/o ignorar las morales tradicionales y dominantes. La inevitable violencia humana llegó con fuerza a ambos personajes sin que ellos la buscaran, pero esa violencia no los apesadumbró ni los derrotó sino que la superaron, no los mató 
sino que los hizo más fuertes de lo que jamás hubieran soñado en sus anteriores vidas pacíficas. Y la locura especial de Max lo hace distinguirse en un mundo donde han sobrevivido los más fuertes, en físico y violencia, y le permitió sobrevivir hasta a esos mismos que ya han sobrevivido en ese universo mecanizado e hiper-hostil.

La violencia puesta como gran obra de arte a través de toda la saga de Mad Max muestra que la ciencia ficción, como la fantasía, puede producir obras de arte profundas, serias y valiosas. Mad Max, como Conan el Bárbaro, tiene en común con las mejores obras clásicas que es tanto fantástica, exagerada e hiperviolenta. Recordemos sólo a La Ilíada, el Antiguo Testamento, La Orestíada, Los Persas, Antígona, la saga de Edipo o El anillo de los Nibelungos (esta última tan admirada por Nietzsche), todas las anteriores obras clásicas tienen su buena dosis de sangre, furia y más. Y cabe decir que así como no son reprensibles estas características en las obras consagradas tampoco deberían de serlo en las nuevas.

El personaje de Max Rockatansky, aún con su superioridad en físico y en actitud sobre los demás integrantes de su universo, no es plenamente un superhombre nietzscheano. Hay una clara razón para lo anterior: Max tiene cierta justificación-razón para emplear la extrema violencia contra otros seres humanos: se encuentra dentro de un mundo postapocalíptico en el que matas o te mueres. Ya referimos que Lefebvre bien comentó que: "La voluntad de poder [...] No es [...] solamente lucha, voluntad de perseverar en el ser, instinto de conservación, sino voluntad de rebasar." (1987;108). En cambio, el superhombre ni justifica ni tiene justificación de su fuerza sino que es su razón de existir, porque es uno de sus medios para progresar, para ser mejor, para demostrar, sin ningún otro objetivo, que es superior a los demás, para impulsar a la humanidad en su mejoría y para evitar que esa misma humanidad se degrade al reblandecerse.

Conan es así un superhombre porque tiene "volun- tad de poder", adolece de una justificación naturalista o darwinista en el uso de su fuerza (para muchos la venganza no es justificación para el uso de la violencia), lo que lo convierte en un ser superior por su propia voluntad. Conan no hace uso gratuito de la violencia tampoco, él hace uso de la fuerza para demostrar consciente e inconscientemente su superioridad guerrera, que es la manera más limpia (la que no recurre a las tretas ni a los engaños) de ser superior a los demás. El bárbaro de Milius queda como una mejor muestra de la bestia rubia de Nietzsche porque sus actos violentos no los hace por supervivencia, como es el caso de Max. Éste no tiene "voluntad de poder", además de que en ocasiones ayuda a los necesitados (véase Mad Max. Fury road, y apréciese la ayuda que da a las esposas de Inmortan Joe), tiene compasión. Por adolecer de la voluntad de poder y por tener ciertas virtudes "judeocristianas", Max no puede llegar a ser un superhombre, aunque tenga ciertas características de éste.

En el cómic Conan fue ladrón, pirata, bandido, explorador, líder militar, pero nunca fue monje, sacerdote, filósofo, científico, político, es decir, nunca engañó con la palabra, nunca se degradó. ${ }^{5}$ Conan nunca se anquilosó, sabe que la petrificación que significa gobernar significa la muerte, cuestión bien representada en el filme de Milius cuando el Bárbaro adquiere su primera espada como hombre libre de un esqueleto perteneciente a un rey que murió sentado en su trono. La voluntad de poder bélico no la perdió nunca Conan, sabía que perderla sería su perdición. Personajes de la misma especie fueron Hércules y Max Rockatansky porque nunca se volvieron sedentarios, nunca trataron de instaurar una dinastía gobernante (no "es seguro que el superhombre es un gobernante [...] [,] los superhombres no gobernarán” (Dannhauser, 2012;796)), nunca intentaron rehacer una civilización decaída o desaparecida, ni nunca intentaron llevar una vida "normal", domesticada y apegada a las normas de sus respectivas culturas.

\section{Referencias}

Dannhauser, Werner J. (2012), “Friedrich Nietzsche”, en Historia de la filosofía política, Leo Strauss y Joseph Cropsey, compiladores, México, Fondo de Cultura Económica, pp. 779-798.

Frey, Herbert (2013), En el nombre de Dyonisos. Nietzsche el nibilista antinibilista, Edda Webbels, traductora, México, Siglo Veintiuno Editores.

Frey, Herbert (2007), La sabiduría de Nietzsche. Hacia un nuevo arte de vivir, Puebla, Universidad de las Américas Puebla.

Frey, Herbert (2005), Nietzsche, Eros y Occidente. La crítica nietzscheana a la tradición occidental, México, Universidad Nacional Autónoma de México/Miguel Ángel Porrúa.

Garzón Bates, Juan (1985), “La valoración de la historia en Nietzsche”, en Teoría, año 2, número 2, México, Universidad Nacional Autónoma de México. 
Lefebvre, Henri (1987), Nietzsche, Ángeles H. de Gaos, traductora, México, Fondo de Cultura Económica.

Nietzsche, Friedrich (2003), Sobre la utilidad y el progreso de la historia. II intempestiva, Germán Cano, traductor, Madrid, Biblioteca Nueva.

Nietzsche, Friedrich (2002), La genealogía de la moral, Andrés Sánchez, traductor, Madrid, Alianza Editorial.

Nietzsche, Friedrich (2001), Así hablaba Zaratustra, México, Ediciones Leyenda.

Nietzsche, Friedrich (1987) Ecce homo. Por qué soy una fatalidad, en Nietzsche (antología) de Henri Lefevbre, Ángeles H. de Gaos, traductora, México, Fondo de Cultura Económica.

Nietzsche, Friedrich (1987 B), Así hablaba Zaratustra, en Nietzsche (antología) de Henri Lefevbre, Ángeles H. de Gaos, traductora, México, Fondo de Cultura Económica.

Nietzsche, Friedrich (1986), Más allá del bien y del mal, Salvador Martínez, traductor, México, Editores Mexicanos Unidos.

Ortiz Delgado, Francisco (otoño 2016) “El estudio de la historia para el perfeccionamiento político y moral. Droysen y Nietzsche.”, en Letras Históricas, no. 15, Guadalajara, Universidad de Guadalajara.

Séneca, Lucio Anneo (1998), Hércules delirante, en Tragedias, Germán Viveros, traductor, México, Universidad Nacional Autónoma de México.

Smith, David C., (agosto 1995) “A Critical Appreciation of John Milius’s Conan the Barbarian”, en Bocere, volumen 1, núm. 3.

Strailey, Jonathan (productor) (2005), documental Conan. The rise of a fantasy legend.

1 El politeísmo principalmente.

2 El judeocristianismo

3 A Conan también se le llamó explícitamente “animal” en el filme. Esto cuando su cronista dice de él que fue un animal encerrado por mucho tiempo. Lo que puede reforzar por igual nuestra interpretación de Conan como un hombre ahistórico nietzscheano, ya que el filósofo alemán reconoce a los animales como los seres ahistóricos por excelencia.

4 Interpretación de los dioses como personas reales que vivieron en algún punto y que con el tiempo fueron divinizadas. Teoría creada por el filósofo Evemero.

5 En su artículo de 1995, David Smith nos pone en claro y detalladamente las diferencias entre el Conan del cómic y el de Milius. 